\title{
An Efficient and General Approach to $\beta$-Functionalized Ketones
}

\author{
Jingliang Jiao, Larry X. Nguyen, Dennis R. Patterson, and Robert A. Flowers II \\ Department of Chemistry, Lehigh University, Bethlehem, PA 18015
}

\begin{abstract}
The oxidation of selected anions $\left(\mathrm{N}_{3}{ }^{-}, \mathrm{SCN}^{-}, \mathrm{I}^{-}\right.$and $\left.\mathrm{Br}^{-}\right)$by ceric ammonium nitrate (CAN) in the presence of substituted cyclopropyl alcohols provides a novel approach to $\beta$-functionalized ketones. The protocol has a number of advantages including short reaction times, ease of reagent handling and mild, neutral reaction conditions. Overall, this method provides an alternative pathway to important starting materials and intermediates in organic synthesis.
\end{abstract}

Ketones substituted in the $\beta$ position are important starting materials in organic chemistry. Among this group, $\beta$-haloketones are extremely useful intermediates in organic synthesis and act as precursors to enones, annulated compounds, heterocyclic derivatives, and dicarbonyl products. ${ }^{1}$ In spite of their importance as precursors to a large range of important intermediates, 2 only a few of methods have been developed to synthesize $\beta$-substituted ketones. ${ }^{3}$ The synthesis of $\beta$-substituted ketones by 1,4-addition of $\mathrm{HX}(\mathrm{X}=\mathrm{Cl}, \mathrm{Br}, \mathrm{I})$ or trimethylsilyl iodide to the corresponding enone are sometimes experimentally inconvenient since the use of reactive or moisture sensitive reagents are required. $3 \mathrm{~b}, 3 \mathrm{~d}$ More recent approaches to $\beta$-substituted ketones, while useful, provide access to a limited range of compounds. ${ }^{4,5}$ As a consequence, the development of new synthetic methods offering a general approach for the introduction of diverse functionality to the beta position of a carbonyl group still constitutes a challenge in organic chemistry.

Cerium(IV) ammonium nitrate (CAN) has found wide applications in carbon-heteroatom bond forming reactions in organic synthesis. ${ }^{6}$ The reported carbon-heteroatom bond formations mediated with CAN include C-Br, C-I, C-S, C-N, and C-Se bonds. These reactions usually involve the generation of heteroatom-centered radicals from the oxidation of anions and addition of the heteroatom radicals to alkenes or alkynes.

Based on this precedent, we reasoned that Ce(IV) oxidation of an anion in the presence of a cyclopropyl alcohol would provide a route to $\beta$-substituted ketones as shown in Scheme 1. Since cyclopropyl units are readily accessible via the Kulinkovich reaction, ${ }^{7}$ the ring opening of cyclopropanols and the carbon-heteroatom bond formation mediated with CAN could provide a novel, efficient, and general approach to a variety of $\beta$-substituted ketones.

The synthesis of substituted cyclopropyl alcohols 1-4 shown in Table 1 were carried out using the Kulinkovich reaction and provided good isolated yields in the range of 63-82\%. In an initial experiment, sodium azide was chosen as the first anion to react with a cyclopropyl alcohol since oxidation of this anion with CAN has been previously reported. ${ }^{8}$ Reaction of $\mathbf{1}$ with $\mathrm{NaN}_{3}$ in the presence of 2 equivalents of CAN in methanol produced a moderate yield (50\%) of the 3-azido-1-phenyl propanone along with dimer and nitrated products as side products. 
Since solvent is known to play an important role in a range of $\mathrm{Ce}(\mathrm{IV})$ initiated bond forming reactions, 9,10 a series of mixed solvent systems were examined to determine the best medium for the reaction as sodium azide is not soluble in many neat organic solvents. Evaluation of a wide range of conditions showed that acetonitrile containing $20 \%$ water provided the highest yield of $\beta$-azido ketone 1a and as a result, this medium was used as the first choice for any anion not soluble in neat solvent. With this initial study completed, the synthesis of $\beta$-azido ketones was extended to several cyclopropanols 2-4. Both aryl- and alkyl- substituted cyclopropanols (1-4) afforded corresponding $\beta$-azido ketones in good to high isolated yields (70-83\%) as shown in Table 1 (entries 1, 5, 9, 13). Next, the CAN mediated strategy was employed to construct other carbon-heteroatom bonds including C-S, C-I, and C-Br. Starting cyclopropanols (1-4) and appropriate ionic compounds $\left(\mathrm{M}^{+} \mathrm{X}^{-}\right)$were used in these transformations. The products and isolated yields are collected in Table 1. It is important to note that column chromatography was required after most reactions and isolated $\beta$-substituted ketones were prone to decomposition in neat form, so they were stored in $\mathrm{CDCl}_{3}$ after isolation.

To test this approach in the formation of carbon-sulfur bonds, ammonium thiocyanate was adopted to supply the thiocyanate anion (entries 2, 6, 10, 14). In these reactions, acetonitrile was employed since ammonium thiocyanate has good solubility in this medium. Once again, the reaction worked well for both aryl cyclopropanols (1 and $\mathbf{2})$ and alkyl cyclopropanols (3 and 4). Very good isolated yields (85-90\%) of $\beta$-thiocyanato ketones (1b-4b) were obtained using this strategy.

Since ketones containing a good leaving group in the $\beta$-position would provide access to a wide range of starting materials for further reaction, iodide and bromide salts were examined. Sodium iodide was chosen as the source of iodide ions and potassium bromide as the source of bromide ions. As shown in Table 1 (entries 3, 7, 11, 15), four cyclopropanols (1-4) were reacted with sodium iodide in the presence of CAN in acetonitrile containing $20 \%$ water. Each reaction provided excellent isolated yields (86-96\%) of the corresponding $\beta$-iodo ketones (1c-4c). Attempts to form $\mathrm{C}-\mathrm{Br}$ bonds using acetonitrile containing $20 \%$ water proved disappointing with isolated yields of the $\beta$-bromoketones varying from $22 \%$ to $46 \%$. In these reactions, oxidation of cyclopropyl alcohols occured predominantly to generate dimers as major products. Bromide ions are considerably harder to oxidize (based on thermodynamic redox potentials). ${ }^{11}$ As a result, oxidation of cyclopropyl alcohols becomes a competitive reaction. To circumvent this process, a two-phase solvent system of dichloromethane and water was utilized. ${ }^{9}$ In this system, CAN and bromide are soluble in the aqueous phase, whereas the cyclopropyl alcohol is only soluble in the organic phase leading to selective oxidation of the bromide ion. This solvent milieu provided isolated yields of $\beta$-bromo products in the range of $71-92 \%$ (entries $4,8,12,16$ ).

To investigate the regioselectivity of more highly substituted cyclopropyl alcohols, 2-ethyl-1phenyl-cyclopropanol, (5) was prepared as a diastereomeric mixture using the Kulinkovich method. Three nucleophiles $\mathrm{N}_{3}{ }^{-}, \mathrm{I}^{-}$, and $\mathrm{Br}^{-}$were reacted with compound $\mathbf{5}$ and the results are shown in Table 2. Examination of the data in Table 2 shows that the observed regioselectivities in the ring-opening reactions are good and provide modest isolated yields. Based on ${ }^{1} \mathrm{H}$ NMR analysis, all the ratios of product 6 to product 7 are $6: 1$ for $\mathrm{N}_{3}{ }^{-}$, $\mathrm{I}^{-}$, and $\mathrm{Br}^{-}$irrespective of the anion utilized (entries 1-3). Products $\mathbf{6 a - c}$ are likely favored due to attack of the $\mathrm{X}$. radical on the least hindered side of the cyclopropyl ring. When the ring opening of 5 was carried out at $0{ }^{\circ} \mathrm{C}$ in the presence of $\mathrm{NaI}$, a marginally improved regioselectivity ( 7 : 1) was obtained albeit with a slightly lower yield (entry 4).

With the success in forming carbon-heteroatom bonds in the beta position of acyclic ketones, we next attempted to synthesize $\beta$-substituted cyclic ketones using the CAN mediated method through the ring opening of a bridgehead bicyclic alcohol. This approach, if successful would 
provide access to tandem ring expansion-addition reactions providing a useful protocol for the synthesis of a medium sized cyclic carbocycle containing a $\beta$-substituted ketone moiety. To examine the practicality of this approach, bicyclic alcohol $\mathbf{8}$ was synthesized employing a previously published procedure ${ }^{12}$ and subjected to the CAN mediated ring-opening reaction in the presence of $\mathrm{N}_{3}^{-}, \mathrm{I}^{-}$, and $\mathrm{Br}^{-}$. All of the data are summarized in Table 3 .

The results in Table 3 show that the ring-opening reaction results in ring-expansion to produce $\beta$-functionlized cycloheptanones for all three anions examined. However, the isolated yields are only moderate due to the presence of side products. Analysis of the reaction mixture using ${ }^{1} \mathrm{H}$ NMR allowed the identification of three major side products as shown in Scheme 2. The side products obtained from this analysis are consistent with oxidation of $\mathbf{8}$, indicating that the rate of reaction of this bicyclic alcohol with CAN is on the same order as the oxidations of anions used in this study. Presumably, the mechanism in this reaction could be different from the one shown in Scheme 1 with oxidation of $\mathbf{8}$ followed by halide addition.

Recent work in our group has shown that the rates of oxidation by CAN are highly dependent on substrate structure and solvent conditions. ${ }^{10,13}$ Based on these previous studies, we reasoned that protection of $\mathbf{8}$ with a more sterically encumbered trimethylsilyl group would reduce the rate of oxidation of substrate while simultaneously allowing us to test the mechanism shown in Scheme 1. Treatment of $\mathbf{1 0}$ with $\mathrm{CAN}$ in the presence of $\mathrm{NaI}$ at $0{ }^{\circ} \mathrm{C}$ provided 3iodocycloheptanone in high yield as shown in Scheme 3.

In conclusion, a novel approach to $\beta$-functionalized ketones with good to excellent yields has been discovered. Considering the mild and neutral conditions of the protocol, short reaction time, ease of reagent handling, high yields, and extensive use of $\beta$-functionalized ketones in organic synthesis, this method provides an alternative pathway to important starting materials and intermediates in organic synthesis. Furthermore, the concomittant ring expansion and $\beta$ functionalization shown in Scheme 3 indicates that this protocol provides a new pathway to make $\beta$-functionalized ketones which are difficult to synthesize in other ways. Detailed mechanistic studies and the use of this method in the synthesis of more complex systems are currently being explored. Results of these experiments will be reported in due course.

\section{Supplementary Material}

Refer to Web version on PubMed Central for supplementary material.

\section{Acknowledgment}

RAF is grateful to the National Institutes of Health (1R15GM075960-01) for support of this work and to Dr. Rebecca Miller and Mr. James Devery at Lehigh University for their useful comments on the manuscript. L. X. N. acknowledges the Center for Emeritus Scientists in Academic Research at Lehigh University for support of his research on this project.

\section{References}

1. House, HO. Modern Synthetic Organic Reactions. 2nd Ed.. Menlo Park, California: Benjamin; 1972. (b) Jung ME. Tetrahedron 1976;32:3-31. (c) Gawley RE. Synthesis 1976:777-794.

2. (a) Ballini R, Barboni L, Giarlo G. J. Org. Chem 2004;69:6907-6908. [PubMed: 15387622] (b) Sonda S, Katayama K, Kawahara T, Sato N, Asano K. Bio. Med. Chem 2004;12:2737-2747. (c) Lagoja IM, Pannecouque C, Van Aerschot A, Witvrouw M, Debyser Z, Balzarini J, Herdewijn P, De Clercq E. J. Med. Chem 2003;46:1546-1553. [PubMed: 12672256] (d) Dohle W, Lindsay DM, Knochel P. Org. Lett 2001;3:2871-2873. [PubMed: 11529778] (e) Sharma VL, Bhandari K, Chatterjee SK. Indian J. Chem., Sect B 1991;30B:876-877. (f) Fujiwara M, Hitomi K, Baba A, Matsuda H. Synthesis 1990:106-109. (g) Narasimhan NS, Patil PA. Tetrahedron Lett 1986;27:5133-5134. (h) Singh H, Batra MS, Singh P. Indian J. Chem., Sect B 1985;24B:131-136. 
3. (a) Marx JN. Tetrahedron 1983;39:1529-1531. (b) Marx JN. Tetrahedron Lett 1971;12:4957-4960. (c) Miller RD, Mckean DR. Tetrahedron Lett 1980;21:2639-2642. (d) Miller RD, Mckean DR. Tetrahedron Lett 1979;20:2305-2308. (e) Johnson CR, Cheer CJ, Goldsmith DJ. J. Org. Chem 1964;29:3320-3323. (f) Murai S, Seki Y, Sonoda N. J. Chem. Soc., Chem. Commun 1974:1032-1033. (g) Kosak AI, Leyland HM. J. Org. Chem 1956;21:733-735.Hilgetag, G.; Martini, A. Preparative Organic Chemistry. NY: John Wiley and Sons, Inc.; 1972. p. 128 (i) Armstrong C, Blair JA, Homer J. J. Chem. Soc., Chem. Commun 1969:103-104.

4. Pourbaix C, Carreaux F, Carboni B. Org. Lett 2001;3:803-805. [PubMed: 11263886]

5. Bandini M, Cozzi PG, Giacomini M, Melchiorre P, Selva S, Umani-Ronchi A. J. Org. Chem 2002;67:3700-3704. [PubMed: 12027683]

6. (a) Nair V, Panicker SB, Nair LG, George TG, Augustine A. Synlett 2003:156-165. (b) Nair V, Balagopal L, Rajan R, Mathew J. Acc. Chem. Res 2004;37:21-30. [PubMed: 14730991]

7. (a) Kulinkovich OG, Sviridov SV, Vasilevski DA, Pritytskaya TS. Zh. Org. Khim 1989;25:2244-2245. (b) Kulinkovich OG. Eur. J. Org. Chem 2004;22:4517-4529. (c) Choi J-R, Cho D-G, Roh KY, Hwang J-T, Ahn S, Jang HS, Cho W-Y, Kim KW, Cho Y-G, Kim J, Kim Y-Z. J. Med. Chem 2004;47:28642869. [PubMed: 15139764] (d) Shirai M, Okamoto S, Sato F. Tetrahedron Lett 1999;40:5331-5332. (e) De Meijere A, Savchenko A. J. Organomet. Chem 2004;689:2033-2055.

8. Trahanovsky WS, Robbins MD. J. Am. Chem. Soc 1971;93:5256-5258.

9. Nair V, Panicker SB, Augustine A, George TG, Thomas S, Vairamani M. Tetrahedron 2001;57:74177422.

10. (a) Zhang Y, Raines AJ, Flowers RA II. J. Org Chem 2004;69:6267-6272. [PubMed: 15357585] (b) Zhang Y, Raines AJ, Flowers RA II. Org. Lett 2003;5:2363-2365. [PubMed: 12816449]

11. Harris, DC. Quantitative Chemical Analysis. 6th ed.. NY: Freeman; 2003.

12. Lee BH, Sung MJ, Blackstock SC, Cha JK. J. Am. Chem. Soc 2001;123:11322-11324. [PubMed: 11697988]

13. Zhang Y, Flowers RA II. J. Org. Chem 2003;68:4560-4562. [PubMed: 12762771] 


$$
\mathrm{X}^{-}+\mathrm{Ce}(\mathrm{IV}) \rightleftharpoons \mathrm{X}^{*}+\bigwedge_{\mathrm{R}}^{\mathrm{OH}} \rightleftharpoons
$$

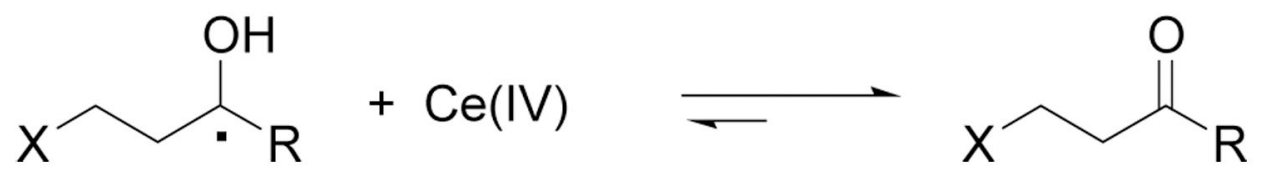

Scheme 1. 


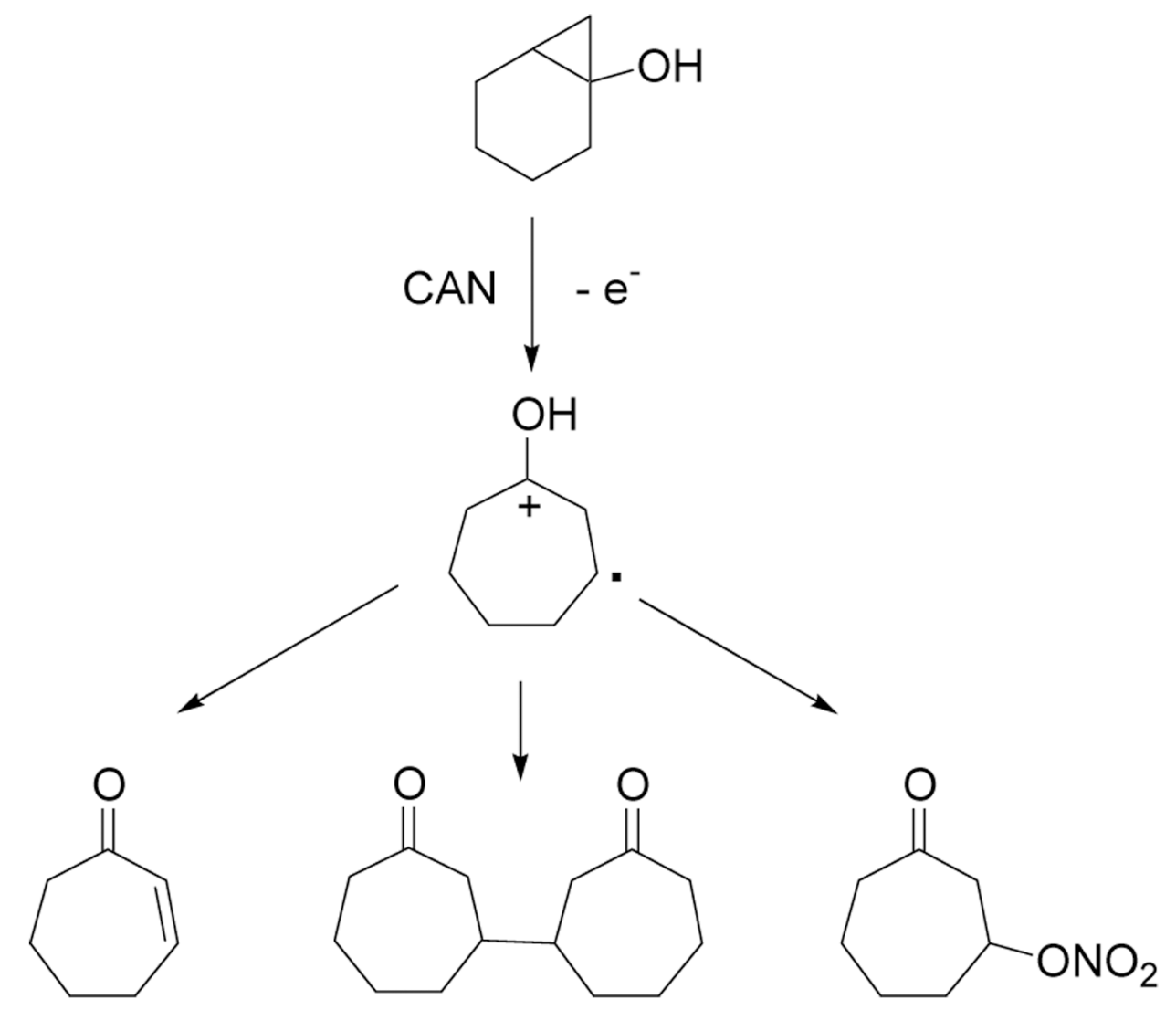

Scheme 2.

Side Products from oxidation of $\mathbf{8}$ 


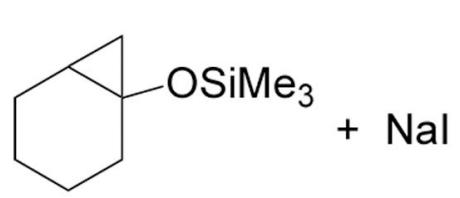

10

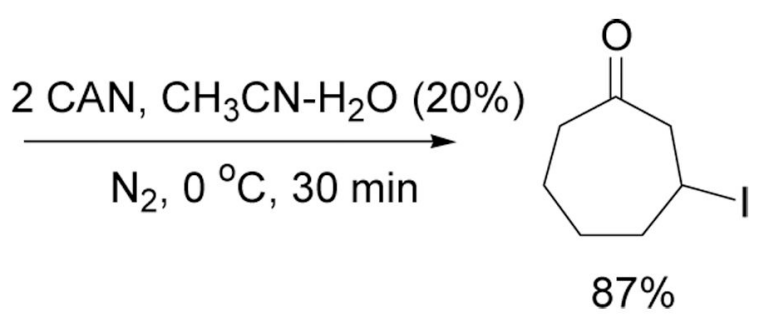

Scheme 3.

Org Lett. Author manuscript; available in PMC 2008 December 4. 


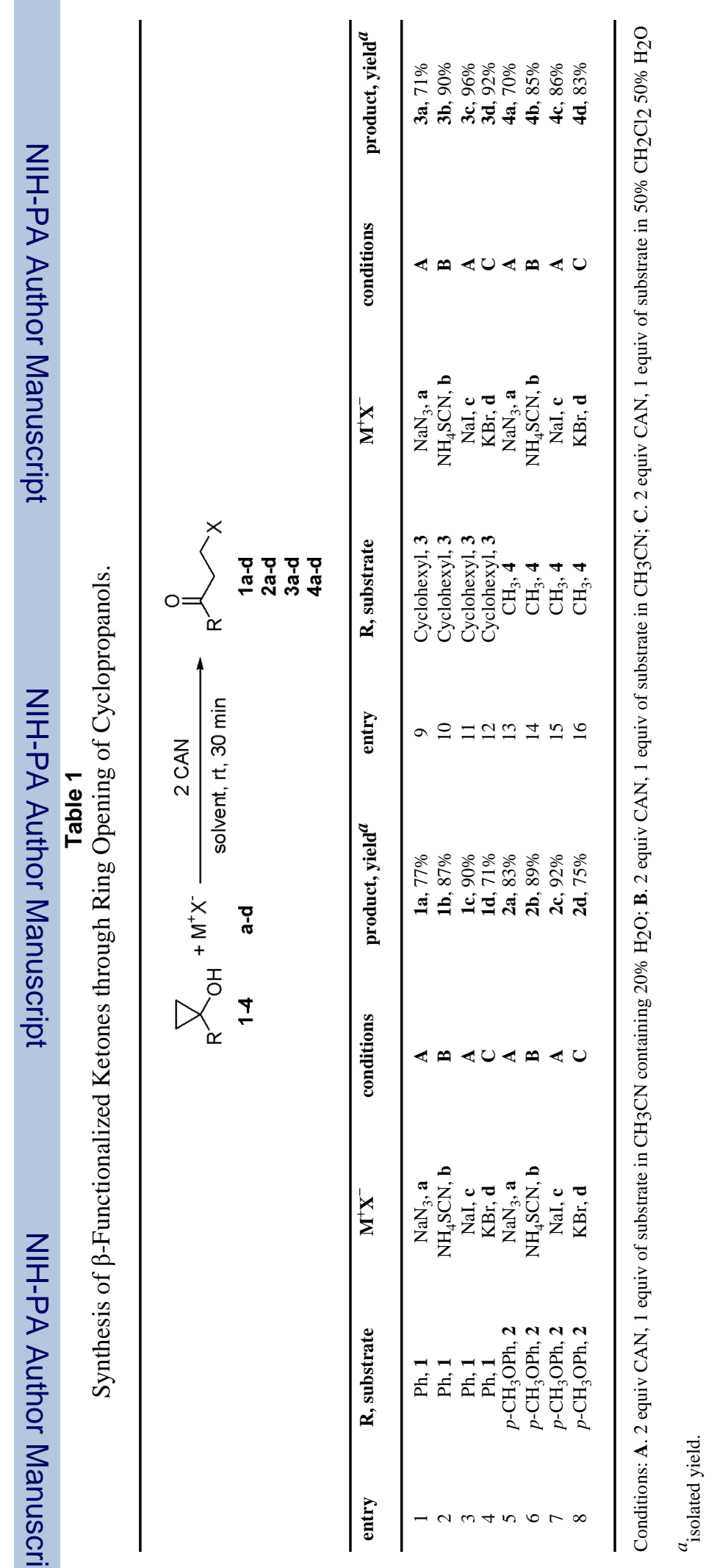

Org Lett. Author manuscript; available in PMC 2008 December 4. 
Table 2

Reactions of Anions with 2-Ethyl-1-phenyl-cyclopropanol.

\begin{tabular}{|c|c|c|c|c|}
\hline & & & $7 a-c$ & \\
\hline entry & $\mathbf{M}^{+} \mathbf{X}^{-}$ & conditions $^{a}$ & major product (yield) & ratio of $6: 7$ \\
\hline 1 & $\mathrm{NaN}_{3}$ & A & $\mathbf{6 a}(48 \%)^{b}$ & $6: 1$ \\
\hline 2 & $\mathrm{NaI}$ & $\mathbf{A}$ & 6b $(66 \%)^{c}$ & $6: 1$ \\
\hline 3 & $\mathrm{KBr}$ & C & 6c $(59 \%)^{c}$ & $6: 1$ \\
\hline 4 & $\mathrm{NaI}$ & A & $6 \mathbf{b}(60 \%)^{c}$ & $7: 1^{d}$ \\
\hline
\end{tabular}

${ }^{a}$ See footnote in Table 1 for conditions.

${ }^{b}$ GC yield.

$c$ isolated yield.

$d_{\text {Reaction run at } 0{ }^{\circ} \mathrm{C} \text {. }}$ 
Table 3

Ring Expansion of Bicyclic Alcohol.

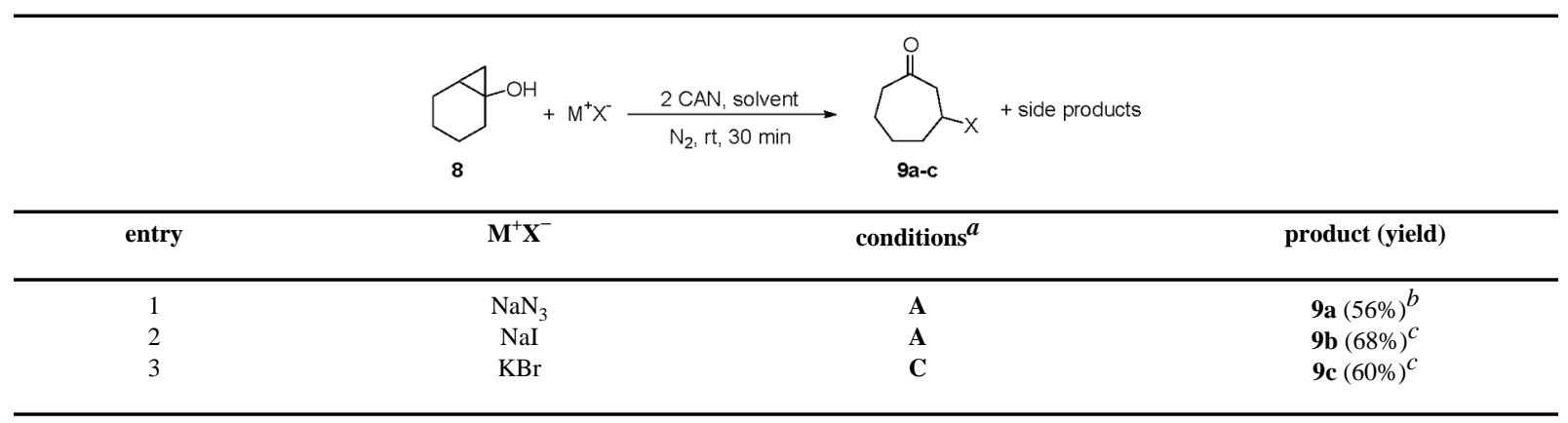

\footnotetext{
${ }^{a}$ See footnote in Table 1 for conditions.

${ }^{b}$ GC yield.

$c_{\text {isolated yield. }}$
} 